\title{
O humor como quebra da convencionalidade
}

Stella E. O. Tagnin

Universidade de São Paulo

Este artigo trata da relação entre a convencionalidade na língua e o humor. Para tanto, apresenta uma categorização de combinações consagradas, desde colocações a fórmulas discursivas, e discute como se prestam à criação do humor. Na qualidade de categorias convencionais, são combinações fixas ou semifixas "prontas para o uso" e decodificadas como um todo. O humor aqui apresentado é lingüístico e obtido pela manipulação/literalização dessas combinações, quebrando a expectativa do ouvinte/leitor. A estreita associação entre o domínio da convencionalidade e a fluência numa língua leva à não compreensão do humor pelo falante não fluente.

This article discusses the relationship between conventionality in language and humor. It puts forward a categorization of ready-made combinations, from collocations to discourse formulas, highlighting the mechanisms in which they are used to create humor. As ready-made combinations, they are fixed or semifixed expressions decoded as a linguistic whole. Humor is achieved by manipulating these combinations so as to cause a breach in the listener's/reader's expectations. Because mastery of linguistic conventionality is closely associated with fluency, and humor relies highly on a breach of conventionality, it is claimed that lack of fluency prevents full comprehension of humor.

Há diversas teorias que se propõem a explicar o humor, entre elas a da incongruência, que é a que adotaremos aqui. Segundo essa teoria, o humor é obtido quando há incongruência entre o que é esperado e o que de fato ocorre. Se entendermos "aquilo que é esperado" como o convencional na linguagem, ou seja, aquilo que foi consagrado pelo uso, podemos afirmar que o humor pode ser obtido através da quebra da convencionalidade.

Mas o que vem a ser a convencionalidade da linguagem? Em primeiro lugar, convém deixar claro que estamos nos referindo a um segundo nível de convencionalidade, não o do signo, mas o nível da combinação das palavras. Estamos falando do nivel sintagmático, das combinações lexicais consagradas ou, nos termos atuais, da fraseologia ou linguagem formulaica, mais especificamente para nossos propósitos, das colocações. 
Foi Fillmore (1979) quem chamou a atenção para a necessidade do conhecimento desse nível de convencionalidade para se adquirir a competência de um falante nativo. Segundo o autor, aquele que o desconhece configura-se como um falante/ouvinte ingênuo, ou seja, de certa forma, estará sempre fazendo uma leitura composicional, isto é, uma leitura literal, ou formando combinações que soam estranhas, não naturais, a um falante nativo. Assim, por exemplo, não saberá que um filme que não tem palavras é denominado em inglês "silent movie", enquanto em português diz-se "cinema mudo" e não "cinema silencioso". Não saberá que em inglês convencionou-se dizer "Gulf of Mexico" enquanto seria gramaticalmente possível dizer-se "Mexico Gulf" ou "Mexican Gulf", a exemplo de "Persian Gulf". "Japanese current" traduz-se por "Corrente do Japão" e não "corrente japonesa", embora essa estrutura também seja gramaticalmente correta. Dessa forma, observa-se de imediato que nem tudo o que é gramaticalmente possível na língua é igualmente natural ou usual.

Podemos também estender a convencionalidade para o âmbito sociocultural, quando deparamos com situações para as quais convencionou-se determinado comportamento. Dessa forma, ao encontrarmos uma pessoa conhecida, pedem as convenções sociais que a cumprimentemos. Nesse caso, não apenas a situação é convencionalizada, mas também é convencionalizada a expressão (ou expressões) que acompanham ou realizam esse comportamento. Há também situações que não demandam uma expressão lingüística, podendo o comportamento ser realizado apenas por um gesto ou expressão facial. Seria o caso de um velório, em que uma pessoa pode externar seus sentimentos apenas com um aperto de mão e um olhar de tristeza ou consternação.

Uma das funções - e talvez a mais importante - dessa linguagem convencionalizada é facilitar a comunicação, pois, na medida em que se trata de combinações conhecidas, consagradas pelo uso, elas são esperadas, de modo que dispensam uma codificação ou decodificação item por item a cada vez que ocorrem. Elas são aprendidas como um todo, como "blocos pré-fabricados", e assim também são produzidas.

Se dominar a convencionalidade de uma língua é essencial para se alcançar a fluência, e se uma forma de criar humor é "quebrar" essa convencionalidade, fica então patente que entender uma tirada humorística baseada nesse tipo de "quebra" é sinal de fluência bastante próxima à de um falante nativo. 
Pois bem, se postularmos que se pode obter humor por meio da quebra dessas convenções, é imprescindível que, antes de mais nada, se conheçam essas estruturas lingüísticas para então poder reconhecer de que forma se deu a ruptura.

Infelizmente, no entanto, pouca atenção tem-lhes sido dada, tanto em cursos de língua, quanto em cursos de tradução (WILLS, 1989; LEPPIHALME, 1996; BALLARD, 1996). Na realidade, poucos também são os estudos de humor em nosso país, principalmente de um ponto de vista língüístico, conforme apontam Possenti (1998, p. 22) e Rosas (2003, p. 134, 158).

Antes de tratar dos mecanismos lingüísticos para obtenção do humor, apresentaremos as categorias convencionais mais relevantes e suas respectivas estruturas (TAGNIN, 1989), com exemplos em inglês e português: ${ }^{1}$

Colocações Nominais - combinações de substantivo com substantivo:

S Prep S: $\quad$ pena de morte, chave de fenda tree of knowledge, justice of the peace

S S: beira-mar, palavra-chave, sofá-cama seashore, key-word, screwdriver

Colocações Adjetivas - combinações de substantivos e adjetivos:

pecado capital, louco varrido, doce ilusão

blithering idiot, sweet dreams, raving mad, social security

Colocações Verbais - combinações de verbos e substantivos, em sua grande maioria, podendo o substantivo ocorrer em função de sujeito ou de objeto. Ocorrem também algumas colocações verbais formadas por verbo mais adjetivo ou advérbio:

\footnotetext{
${ }^{1}$ Como nosso objetivo é exemplificar as estruturas, os exemplos nas duas línguas não serão necessariamente traduções um do outro, pois nem sempre as estruturas são correspondentes: por exemplo, "evening course", uma colocação nominal em inglês, seria traduzida por "curso noturno", uma colocação adjetiva em português. Em outros casos, uma estrutura consagrada pode nem ser traduzida por um fraseologismo na outra, como ocorre, por exemplo, com "serial killer", que não tem equivalente em nossa língua.
} 
V S [obj]: fazer uma refeição, aviar uma receita, tomar uma decisão

have a meal, fill a prescription, make a decision

S [suj] V: $\quad$ rio corre, nariz escorre, cão ladra river flows, nose runs, dog barks, volcano erupts

V Adj: $\quad$ ficar doente take ill, get sick

Colocações Adverbiais - essas são de dois tipos:

Adv Adj: fartamente ilustrado, imensamente grato lavishly illustrated, happily married

V Adv: $\quad$ pagar caro, amar profundamente, mentir descaradamente pay dearly, love deeply, lie outright

Binômios - combinações de dois itens da mesma categoria gramatical, usualmente numa estrutura de coordenação. Podem ser irreversíveis ou reversíveis. Observa-se que em certos casos a ordem difere entre as línguas, mesmo quando compostos por itens lexicais cognatos, a exemplo de vivo ou morto em português, em oposição a dead or alive em inglês:

Irreversíveis: vivo ou morto, capa e espada, ou tudo ou nada dead or alive, cloak and dagger, hit and run

Reversíveis: preto e branco/branco e preto day and night/night and day

Trinômios: casa, comida e roupa lavada; bom, bonito e barato red, white and blue; a, b, c

Expressões Idiomáticas - expressões cujo significado não pode ser determinado a partir da somatória dos significados individuais dos itens que a compõem. É provavelmente a categoria mais conhecida, ainda que não a mais freqüente ou recorrente na língua cotidiana:

tirar o sarro, chover no molhado, pegar no pé

pull sb's leg, kick the bucket, hit the hay 
No nível pragmático da língua temos as fórmulas discursivas, dentre as quais podemos ressaltar as seguintes:

Ditos populares: Saco vazio não pára em pé.

Beware of Greeks bearing gifts.

Citações: $\quad$ Ser ou não ser, eis a questão.

To be or not to be, that's the question!

Provérbios: $\quad$ Nem tudo que reluz é ouro.

All that glitters is not gold.

Marcadores conversacionais - expressões que gerenciam a conversação:

Não concordo, O que você acha?, Certo?

I'm afraid I don't agree, What do you think?, Right?

Estruturas de polidez

$$
\begin{aligned}
& \text { Would you mind } \mathrm{X} \text { ? } \\
& \text { Você se importaria de X? } \\
& \text { I wonder if I could X? } \\
& \text { Será que eu poderia X? }
\end{aligned}
$$

Fórmulas de Rotina - expressões que fazem parte do repertório usado no convívio social, constituindo-se, no geral, de um enunciado que demanda uma resposta, ou pelo menos um "reconhecimento" por parte do interlocutor:

Agradecimento: A: Obrigado/a, Muito obrigado/a.

B: De nada, Não por isso.

A: Thank you; Thank you very much, Thanks a lot.

B: You're welcome; That's OK, My pleasure.

Desculpas: $\quad$ A: Desculpe, Sinto muito.

B: Não foi nada, Não tem problema.

A: I'm sorry; I'm awfully sorry.

B: That's OK.

Elogios: $\quad$ A: Que elegância!

B: Obrigado. 
A: Que blusa linda!

B: Obrigada. Ganhei da minha tia, Comprei numa liquidação, foi baratinha;

Às ordens.

Também gosto dela.

A: What a beautiful blouse!

B: Thanks, I like it too.

Oh, it's just an old rag!

Cumprimentos: Bom dia, Boa noite; Como vai? Tudo bem? Good morning, Good evening; How are you? Hi!

Despedidas: $\quad$ Boa noite, Até logo, Tchau, Até amanhã.

Good night, Good bye, Bye bye, See you tomorrow.

Há ainda uma última categoria, composta pelas fórmulas situationais, que engloba comentários peculiares a determinadas situações, ou seja, a partir desse comentário pode-se inferir o que está acontecendo:

Não seja criança!

Olha o roto falando do esfarrapado!

Não é o que você está pensando!

Não é da sua conta.

É ver para crer.

Act your age!

That's the pot calling the kettle black.

It's not what you think.

It's none of your business.

I'll believe it when I see it.

Como dissemos, uma das formas de se criar humor é manipular essas categorias convencionais, valendo-se, principalmente, de quatro fenômenos lingüísticos: 
- homonímia, que consiste no fato de duas palavras terem a mesma grafia e o mesmo som, porém serem etimologicamente distintas: banco de jardim vs. banco como instituição financeira;

- homofonia, que consiste em duas palavras terem o mesmo som, porém grafias distintas: cesta vs. sexta;

- polissemia, que consiste no fato de uma palavra ter diversos sentidos, porém etimologicamente relacionados: banco (instituição financeira) vs. banco de dados;

- paronímia, que consiste em duas palavras de som ou grafia similares.

Para que o humor seja bem sucedido, é preciso que autor e leitor compartilhem a linguagem que está sendo manipulada. Se o leitor/ ouvinte não conhecer a expressão convencional e, por conseguinte, não se aperceber da manipulação, não compreenderá o humor ou, nos termos de Fillmore (1979), constituirá um "falante ingênuo". Podemos, com grande proveito, estender a noção de Fillmore ao tradutor, postulando que um "tradutor ingênuo" é justamente aquele que desconhece a convencionalidade de uma língua de modo que não é capaz de detectar sua ocorrência no texto que traduz, deixando assim de recuperá-la no texto traduzido. Isso, conforme o caso, pode passar totalmente despercebido ou ter seríssimas conseqüências, como no caso do humor baseado na quebra da convencionalidade.

A seguir examinaremos alguns exemplos de humor obtido por meio da manipulação das categorias convencionais acima descritas.

Num calendário de mesa que sugere para cada dia do ano uma "palavra ou expressão que não existe, mas que deveria existir", encontramos "truth decay" definida como "The erosion of a public figure's credibility". O neologismo só tem graça se percebermos tratarse de um caso de paronímia com a colocação nominal "tooth decay".

Outro jogo de palavras com uma colocação nominal ocorre numa citação atribuída à atriz Zsa Zsa Gabor: "I'm a marvellous housekeeper. Every time I leave a man I keep his house". Trata-se de um caso de polissemia do verbo "keep": o humor é obtido justamente porque se espera uma leitura do verbo como "cuidar" (keep a house), enquanto o contexto nos leva a outra: "ficar com". O mecanismo, nesse caso, é de fácil reprodução em português, devido à polissemia de "dona": "Sou uma ótima dona de casa. Cada vez que largo um homem fico dona da casa dele." 
Numa tira dos personagens americanos Frank \& Ernest, os dois estão diante de um prato de comida, mas, pela expressão, parecem não estar apreciando o que comem.O dono da lanchonete diz, "It is continental breakfast. We just didn't say which continent." Há aqui um processo de literalização, ou seja, a colocação nominal "continental breakfast", que se refere a um tipo de café da manhã servido em hotéis e que consiste, em geral, de café, pão, manteiga, geléia e talvez queijo, passa a ter uma leitura literal em que "continent" adquire seu significado denotativo de "grande massa de terra cercada por águas oceânicas", o que então permite o comentário "Só não dissemos de que continente." Caso queiramos reproduzir esse jogo de palavras em português, poderíamos optar por "É café colonial, sim, só não dissemos de que colônia."

O mesmo tipo de literalização ocorre com uma colocação adjetiva num comentário de Woody Allen: "Last night I discovered a new form of oral contraceptive. I asked a girl to go to bed with me and she said no." Na colocação, o adjetivo "oral" é semanticamente moldado por "contraceptive" (ALLERTON, 1984), adquirindo o sentido de "por via oral". Na seqüência do comentário, entretanto, o leitor se vê obrigado a reformular sua leitura, atribuindo ao adjetivo o sentido de "verbal". Há uma passagem do convencional/esperado para o não convencional/ inesperado. A língua portuguesa permite a reprodução desse mecanismo: "Ontem à noite, descobri uma nova forma de contraceptivo oral. Convidei uma garota para ir prá cama comigo e ela disse não.”

No exemplo seguinte temos um binômio paronímico formado por uma colocação adjetiva e uma nominal: um sapo entra numa lanchonete e pede "a Bug Mac and a side of flies". Só é possível apreciar o jogo de palavras se conhecermos o pedido mais comum no MacDonald's e nos dermos conta da substituição de "Big" por "Bug" e "fries" por "flies". Parte do jogo pode ser recriada em português com "um Big Mac e uma porção de baratas."

Um caso de homofonia ocorre numa tirinha em que Frank \& Ernest vêem um cartaz que diz "fission chips" e batem à porta do local. A pessoa que atende tenta lhes explicar que o que lá vendem são partes para computadores. Fica implícito que os personagens "leram" "fish and chips". O leitor que desconhece o binômio não pode apreciar o humor.

Pode-se também obter humor criando-se um novo binômio ou trinômio. Nesse caso, o inesperado é justamente a nova criação, que deve seguir, no entanto, os moldes de uma categoria convencional. Assim, 
temos numa tirinha a ilustração de uma cadeira com um cartaz "Frank \& Ernest's Chair \& Snack", enquanto os personagens comentam: "We thought we'd start small and work up to a bed and breakfast". O humor reside exatamente na contraposição de um binômio consagrado "bed and breakfast" com um binômio ad hoc "chair and snack". Algo semelhante ocorre em outra tira, quando os mesmos personagens estão saindo do dentista e um deles diz "I like him because he's quick - just drill, fill and bill." É o caso de um trinômio criado, inclusive, com uma das características que mais facilitam a consagração: a rima. Enquanto o primeiro é de difícil re-criação em português - não cabe, no escopo deste artigo, uma discussão sobre casos de intraduzibilidade -, o segundo tem no trinômio "fura, obtura e fatura" uma solução à altura do original.

No exemplo a seguir a literalização dá-se com uma colocação verbal: "The money in my account must have been laundered... it certainly has shrunk ". A co-ocorrência com "money" atribui a "launder" um sentido figurado específico, que é reinterpretado quando "money" co-ocorre com "shrunk". É a polissemia do verbo que permite essa dupla leitura. O mesmo jogo pode ser reproduzido em português com o verbo "lavar", que co-ocorre com dinheiro em contexto similar ao inglês.

As expressões idiomáticas também são fonte constante de humor, não as expressões per se, mas a dupla leitura que permitem. Lembremonos de que as expressões idiomáticas são aquelas em que o significado total não corresponde à somatória do significado de cada um dos seus elementos. Diversos estudos psicolingüísticos atestam que o tempo de decodificação de uma expressão idiomática é menor do que o de sua contrapartida literal. Isso significa que se determinada seqüência de palavras tanto pode ter uma leitura literal quanto idiomática, a idiomática é a esperada. Assim, a quebra dessa expectativa causaria humor. É o caso de uma senhora que diz: "I'd like to paint the town red, but I'm married to Mr. Turpentine here." A primeira leitura é idiomática, no sentido de "fazer uma grande farra". No entanto, quando se chega ao final do texto, o nome do marido - Sr. Terebentina - aciona a leitura literal, ou seja, há uma literalização da expressão. Uma possível tradução para o português seria: "Bem que eu gostaria de pintar e bordar, mas sou casada com o Sr. Terebentina."

As fórmulas discursivas também se prestam a esses jogos lingüísticos, pois podem ser polissêmicas e passar por processo de literalização. Numa tirinha uma garçonete pergunta: "Can I get you 
something to eat?", ao que recebe a resposta, "No, thanks, I'm stuffed". Ocorre que a resposta é dada por um animal embalsamado, o que aciona a literalização de "stuffed".

Um exemplo de paronímia ocorreu no título de uma matéria jornalística: "Ear today, gone tomorrow". O artigo abordava o caso de Mike Tyson ter arrancado um pedaço da orelha de seu adversário. Para entender o humor, é preciso perceber que o título alude a uma conhecida frase "Here today, gone tomorrow".

Um último exemplo deixa a incongruência bastante evidente. Trata-se novamente do título de um artigo de revista: "Do you, Sir, take this man...". A incongruência aqui dá-se no nível sociocultural e não apenas lingüístico. Em primeiro lugar, é preciso reconhecer a fórmula empregada pelos padres ao celebrarem um casamento. Em segundo, observar a incongruência entre "Sir" e "this man", uma vez que o que se espera é "Do you, Sir, take this woman...", pois os casamentos se realizam, em geral, entre membros de sexos opostos. No entanto, essa matéria trata justamente de um casamento entre homossexuais.

Não é por acaso que os dois últimos exemplos são de textos jornalísticos. Além de entretenimento, o humor também pode ter o objetivo de chamar a atenção do leitor, justamente pela quebra de expectativa, função bastante evidente naqueles títulos. Essa função também é extremamente comum em textos de propaganda, cujo objetivo primordial é chamar a atenção do leitor. Uma expressão consagrada, por sua própria característica, passa desapercebida: ela é tão comum que não chama a atenção, razão pela qual é preciso "remotivá-la" para que salte à vista e cumpra seu objetivo.

Ter o domínio da convencionalidade tem sido associado à fluência na língua (PAWLEY \& SYDER, 1983). Compreender o humor numa língua estrangeira é considerado o grau máximo de fluência nessa língua. Uma vez que grande parte do humor é obtida pela quebra da convencionalidade, pode-se concluir que conhecer as categorias convencionais abordadas neste artigo é um passaporte para a compreensão do humor. 


\section{Referências}

ALLERTON, D. J. Three (or four) levels of word cooccurrrence restriction. Lingua 63, p. 17-40, 1984.

BALLARD, M. Wordplay and the Didactics of Translation. The Translator, v. 2, n. 2, p. 333-346, 1996.

FILLMORE, C. J. Innocence: A Second Idealization for Linguistics. Berkeley Linguistic Society 5, p. 63-76, 1979.

LEPPIHALME, R. Caught in the Frame. A Target-Culture Viewpoint on Allusive Wordplay. The Translator, v. 2, n. 2, p. 199-218, 1996.

PAWLEY, A.; SYDER, F.H. Two puzzles for linguistic theory: Nativelike selection and nativelike fluency. In: RICHARDS, J.C.; SCHMIDT, R.W. (Ed.). Language and communication. New York: Longman, 1983. p 191-226.

POSSENTI, S. Os humores da lingua: análises lingüísticas de piadas. Campinas: Mercado de Letras, 1998.

ROSAS, M. Por uma teoria da tradução do humor. D.E.L.T.A.. v. 19: Especial, p.133-161, 2003.

TAGNIN, S. E. O. Expressões idiomáticas e convencionais. São Paulo: Ática, 1989.

WILLS, W. Anspielungen. Zur Manifestation von Kreativität um Routine in der Sprachverwendung. Tübingen: Max Niemeyer, 1989. 